\title{
L'autolesió corporal: propostes per a una interpretació cultural del símptoma
}

\author{
Lina Cristina Casadó Marín \\ Doctora en Antropologia Social i Cultural, Universitat Rovira i Virgili \\ linacristina.casado@urv.cat
}

Resum: En la propera edició del DSM-V, que es preveu que surti publicada l'any 2013, l'autolesió corporal apareixerà definida com un nou trastorn mental sota l'etiqueta diagnòstica de non-suicidal self-injury (NSSI). Un dels principals motius que des de l'American Psychiatric Association (APA) es donen a la creació de la categoria clínica té a veure amb l'augment de la incidència de la conducta autolesiva i la necessitat d'implementar mesures terapèutiques especifiques a aquestes accions. Al fil del que la nova edició del DSM planteja, en aquest article presento una reflexió crítica al voltant d'aquest procés. Els eixos sobre els quals pivota aquesta dissertació se centren, d'una banda, a reflexionar al voltant de les implicacions que pot generar la construcció de l'autolesió corporal com un problema de salut que afecta especificament els joves, $i$, de l'altra, a reivindicar la necessitat de recuperar les narratives $i$ les interpretacions que els joves fan del seu simptoma. Amb relació a aquest darrer punt, les possibilitats que l'etnografia i l'ús de les narratives ens permet anar més enllà dels limits interpretatius del model biomèdic, $i$ ens obre la porta a la dimensió relacional de l'autolesió com a simptoma social.

Paraules clau: joves, autolesió corporal, medicalització, DSM-V, narratives.

Abstract: : In the fifth edition of the Diagnostic and Statistical Manual of Mental Disorders (DSM-V), due for publication in 2013, self-injury will be included as a new mental disorder under the diagnostic label of non-suicidal self-injury (NSSI). One of the main reasons the American Psychiatric Association (APA) bas given for creating this new clinical category is the rising incidence of self-injurious behaviour, especially among young girls, and the need to adopt specific therapeutic measures against these actions. In this paper, drawing on the proposed content of DSM-V, I present a critical reflection on this process. My analysis rests on two main themes: the possible implications of the construction of self-injury as a health problem that affects young people in particular and the need to recover young people's narratives and interpretations of the symptom. In relation to this last point, I draw on my field experience to demonstrate how narratives can be a gateway to associating and understanding self-injury as a social symptom.

Keywords: Young, bodily self-harm actions, medicalization, DSM-V, narratives. 


\section{Introducció}

Scars are stories, history written on the body...

K. Harrison (1993:10)

L'essència de l'antropologia, plantejava Lévi-Strauss (1987), consisteix a reintegrar a la racionalitat tots aquells fenòmens o accions humanes que a priori semblen patològics o incomprensibles. Un dels objectius previstos en aquest article tracta precisament d'això, de donar una lectura al que és etiquetat de bogeria, de reflexionar sobre els processos mitjançant els quals es construeix, en un determinat context cultural, el diagnòstic de malaltia mental.

La primera vegada que vaig sentir parlar de les autolesions corporals com una forma de canalitzar els "nervis" va ser l'any 2005. Certament, era un aspecte que no esperava trobar, va sorgir espontàniament $i$ inductivament del camp, va ser una troballa casual que va aflorar en algunes de les entrevistes realitzades a joves ingressades en una unitat de Trastorns de la Conducta Alimentària de Barcelona. De la troballa casual més endavant va venir la problematització i més endavant la realització d'un projecte de recerca (l'equivalent a l'actual treball de fi de màster, llavors DEA — diploma d'estudis avançats en Antropologia Urbana-) que vaig defensar l'any 2007. D'aquesta manera, el projecte de DEA se situava a l'inici del meu recorregut, ja que em va ajudar a posar sobre el paper reflexions sobre marcs teòrics i metodològics que més endavant es van convertir en la base sobre la qual es construiria el treball de camp de la tesi doctoral.

Un any abans de presentar el projecte de DEA, l'any 2006, mentre començava a assentar els fonaments al voltant del projecte "símbolos y significados de las acciones autolesivas corporales" va saltar l'alarma als mitjans de comunicació de massa en relació amb el que es va considerar l'“epidèmia silenciosa de l'autolesió” (Truth Hurts, 2006). ${ }^{1}$ Si bé aquests programes estaven interessats

1. Les dades del Truth Hurts (2006) posaven sobre la taula el fet que al Regne Unit 1 de cada 15 joves d'entre 12 i 25 anys s'autolesiona. Arran d'aquest primer informe, van començar a sorgir investigacions i programes d'intervenció als Estats Units - programa d'investigació en self-injury behaviour de la Universitat de Cornell i grup SAFE (Self-abuse Finally Ends) de la Universitat de Columbia, al Regne Unit - National Self-Harm Network, Harmless i el Centre for Suicide Research de la Universitat d'Oxford-i al Canadà el programa SAFE Alternatives. 
a situar epidemiològicament el fenomen de l'autolesió entre els joves i a desenvolupar estratègies terapèutiques per evitar aquest tipus d'acció, cap d'ells no es va plantejar fer una investigació en profunditat sobre els marcs subjacents a la realització d'aquest tipus d'acció ni tampoc es van interessar a analitzar per què es presentava, sobretot, en noies joves. Paral.lelament a aquests programes, van començar a aparèixer treballs d'estil quantitatiu que tenien com a objectiu situar les dimensions del fenomen. Amb relació a aquest punt, i per donar algunes dades, Madge et al. (2008) van situar la prevalença d'autolesió corporal entre el $2 \%$ i el $6 \%$ de la població general i altres estudis (Hawton et al., 2008) van posar de manifest que la prevalença en el nombre de dones triplicava el d'homes. Aquest $\mathrm{i}$ altres treballs em van servir d'exemple per veure com, tot $\mathrm{i}$ que molts dels articles revisats assenyalen la categoria gènere i edat com una variable determinant, tots es queden en la simple dada descriptiva, sense indagar els factors culturals que rauen en la construcció social del cos i les experiències subjectives que impulsen els joves a autolesionarse corporalment.

En aquest context, aquest article sorgeix de la necessitat de reflexionar i presentar una anàlisi crítica del procés mitjançant la qual l'autolesió corporal apareix definida com un nou trastorn mental. Al fil del que planteja la nova edició del DSM, a la primera part de l’article presentaré una reflexió sobre diferents escenaris on l'acció autolesiva corporal és present: de vegades interpretada com una pràctica normal, d'altres com una conducta desviada. El comú denominador a aquestes situacions és que ens serveix per, mitjançant el seguiment de l'acció autolesiva, entrar en la particularitat de les narratives, endinsar-nos en microhistòries que condensen universos de significat. L'objectiu en aquest punt és posar de manifest les regles que regeixen la construcció del fet social (l'autolesió) com a acció significant, això és, com un símbol des d'un punt de vista hermenèutic (Ricoeur, 2003).

El punt de partida que presento té a veure amb la manera com els signes (pensant ara en l'àmbit més físic) pels quals es manifesta tant individualment com colllectivament l'acció no tenen normalment una seqüència lineal a l'estil "mateixa acció, mateixa interpretació", sinó que un mateix signe condensa una sèrie de significats. Així, en termes de Ricoeur, l'autolesió és, si fa no fa, "un símbolo que responde a una estructura de significación en la que un sentido directo, primario, literal, designa además otro sentido indirecto, secundario, figurado, y esta circunscripción de las expresiones de doble sentido constituyen 
propiamente un campo hermenéutico, y es nuestra tarea la labor de interpretarlos" (Ricoeur, 2003: 16).

Analíticament, el fet d'abordar les autolesions corporals com a fets socials (Durkheim, 1987) de naturalesa relacional (Menéndez, 1985; 1997; 2003) ha permès observar com una mateixa acció adquireix un significat o un altre en funció del marc que legitima/estigmatitza l'acció, alhora que ha facilitat el fet de reflexionar al voltant de les relacions sobre les quals es construeix l'autolesió com a malaltia mental. De fet, les autolesions han permès endinsar-nos en tota una trama d'interrogants — per què el cos, per què autoagressions i per què, com senyala la major part dels treballs quantitatius revisats, sobretot en noies joves - que hem hagut de desxifrar culturalment.

És en aquest punt que crec que la cultura és central, i no perquè m’hagi proposat realitzar una comparació transcultural dels sentits de l'autolesió corporal, sinó perquè el seguiment de l'acció ha servit de boc expiatori (Girard, 1986) per qüestionar la naturalesa del signe, així com també els paràmetres segons els quals es construeix des de la nosografia psiquiàtrica la nebulosa de l'espai liminar (Turner, 1980) que separa la normalitat de la desviació en un determinat context cultural.

\section{L'autolesió corporal del signe al símptoma i al síndrome}

Erwin Ackerknecht (1971) apuntava a mitjans del segle passat que des d'un punt de vista mèdic les malalties mentals tenen el gran desavantatge que no poden definir-se mitjançant conceptes anatòmics o bioquímics i una de les principals contribucions de l'Antropologia Mèdica en aquest àmbit és que, seguint la tesi d'Ackerknecht, ofereix la possibilitat d'evidenciar l'arbitrari que sustenta la construcció social de la malaltia mental.

Sobre el que va plantejar Ackerknecht ara ja fa uns quants anys i per començar a desgranar el tema que tractem, la primera qüestió epistemològica que vaig haver de resoldre en començar a treballar sobre autolesions corporals tenia a veure amb el fet de traspassar la frontera d'allò evident, amb el fet de ser el prou hàbil per trencar el que Durkheim anomena prenocions (1987) o que Bourdieu (1976) defineix com a sentit comú social. En definitiva, es tractava de presentar 
una reflexió en clau fenomènica sobre diferents contexts on l'autolesió, sense ser considerada una conducta estigmatitzada, ${ }^{2}$ és present.

Per tal de concretar aquests escenaris, ens va resultar de gran utilitat l'elaboració d'un quadre (quadre 1. Escenaris de l'autolesió) construït per oposicions: d'una banda, vaig introduir el concepte d'autolesions normalitzades versus autolesions estigmatitzades i, de l'altra, les autolesions públiques versus les autolesions privades. Dins la categoria d'autolesions normalitzades, vaig pensar en determinades formes d'art corporal (tatuatges, pírcings i escarificacions), accions autolesives en context ritual (cilicis, flagel+lacions, dejú, crucifixions, etc.) i l'autolesió en el medi penitenciari (chinar-se, cosir-se la boca, empassar-se objectes, etc.). Dins la categoria d'autolesió pública, vam pensar també en determinats rituals (religiosos i de curació) que inclouen la mortificació del cos. En l'autolesió privada, vaig pensar en l'autolesió en situacions de conflicte bèllic - autolesions per evadir la primera línea de foc en el camp de batalla-, en el medi laboral, com a signe d'identitat entre els joves i també les que són interpretades sota l'etiqueta diagnòstica del trastorn/malaltia mental. Aquest quadre em va permetre repensar l'acció autolesiva en termes no exclusivament patològics, sinó com una pràctica que pot ésser interpretada (d'aquí la importància de recuperar-ne la lectura hermenèutica) i viscuda (des d'un posicionament fenomenològic) de moltes maneres, i el context és el marc que legitima o estigmatitza l’acció.

2. Aquí utilitzem conscientment el terme estigma (Goffman, 1970) per la forta càrrega que simbòlicament va associada a l'acció quan és interpretada en clau de conducta desviada. 


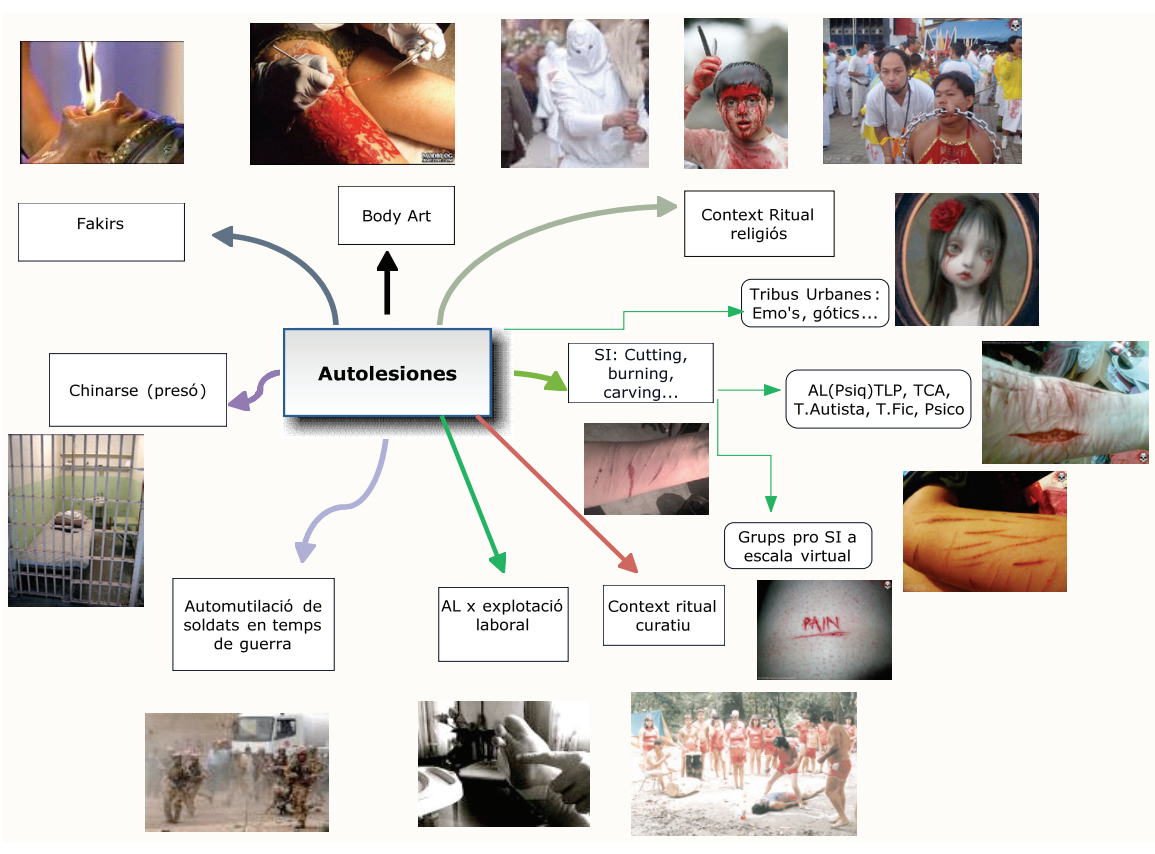

Quadre 1. Escenaris de l'autolesió. Elaboració pròpia.

Van Dongen (2004) utilitza el concepte "the work with culture" per referir-se als marcs que vaig fer servir en l'anàlisi. Per a Van Dongen, the work with culture fa referència a "the process of manipulation, bricolage and non-conventional use of symbolic forms" (2004: 20). Per a l'autora, que específicament va centrar el seu treball en la interpretació de la psicosi,"rather than viewing the presentations of psychotic patients as signs of a disorder, I examine them as a cultural forms expressing severe misery and distress. The stories of psychotic people derive from something deep and fundamental. Kirmayer (1993: 173) says they contain metaphors, myths and archetypal images that emerge from interactions between the person and society" (Van Dongen, 2004: 20).

Seguint la idea de fragilitat i arbitrarietat sobre la qual se sustenta la construcció de la normalitat i d'acord amb Cangilhem (1971), el límit entre la normalitat i la patologia és molt problemàtic i les lleis que regulen la raó les trobem implícitament escrites en la societat. La idea apuntada per Cangilhem va ser posteriorment treballada per Michel Foucault, que va començar el seu treball 
realitzant una crítica al concepte psicològic de normalitat - distingint-lo epistemològicament del de fisiopatologia - i que va culminar aplicant-lo a làmbit de la medicalització i la biopolítica.

Ruth Benedict, l'any 1934, ja apuntava la idea que la normalitat ve definida culturalment. Benedict, que va analitzar els estats de trànsit entre els shasta, els zulus, els dobu i l'homosexualitat entre els berdache (entre d'altres), va demostrar que una persona no es pot considerar "anormal" sense tenir en consideració la seva situació històrica i cultural. Continuant amb la distinció normal/anormal, per a Georges Devereux és la psiquiatria qui ha de determinar la ubicació de la frontera que separa allò normal del que no ho és (Devereux, 1973). Tot i que Devereux, psiquiatra de formació psicoanalista, va introduir la variable cultura en els seus estudis d'etnopsiquiatria, el que va fer va ser tractar de confrontar el concepte de cultura amb allò normal i anormal (Devereux, 1973: 26). Per a Devereux els criteris de normalitat són absoluts, és a dir, independents de la cultura, i la anormalitat es manifesta de diferent manera en funció del context cultural. D'aquí sorgeix el concepte d'ethnic disorder ${ }^{3}$ — desordre ètnic- de Devereux.

Directament derivat del concepte de desordre ètnic, Raymond Prince l'any 1985 va parlar dels culture-bound-syndromes (síndromes delimitats culturalment) per definir "a collection of signs and symptoms - excluding notions of cause - which are restricted to a limited number of cultures primarily by reason of their psychosocial features" (1985: 201). Prince va parlar de l'anorèxia nerviosa i del brain-fag com a exemples de síndromes delimitats culturalment.

De les propostes d'aquests autors m'interessa destacar la necessitat (a través de la descripció de trastorns ètnics, malalties folk o culture-bound-syndromes) d'entendre la racionalitat cultural de determinants malestars. Així, doncs, i si bé en terminologia biomèdica l'autolesió és un signe, això és, "una manifestació objectiva d'un estat patològic" (DSM-IV-TR), en termes culturals l'autolesió és polisèmica. Els símptomes - percepcions subjectives - i significats que trobem al darrere de l'acció autolesiva són d'allò més variats: des de culpa i expiació, control i poder fins a forma de resistència o alleujament, tret d'identitat, també vinculat a la somatització de l'angoixa, dolor i esmussament emocional. A partir d'aquesta idea ens adonem que els significats que hi ha al darrere d'un

3. Per a Devereux (1973: 73) els desordres ètnics estan arrelats al caràcter ètnic, i dins el seu esquema cultural forma una estructura coherent tant en l'evolució com en les manifestacions. 
mateix signe poden ser d'allò més variats i ens obliguen que per interpretar-los ens haguem d'ubicar en els dominis culturals en els quals s'insereixen.

\section{3. "The portrait of the typical self-injurer": la construcció biomèdica del terme}

Don't go crazy, but if you do, you must behave as follows

G. Devereux (1980: 34)

Si bé els escenaris en què l'autolesió corporal és present són força heterogenis, en aquest punt presentaré una reflexió sobre les ambigüitats implícites en el terme. Bàsicament perquè acotar-les implica un exercici de reflexió sobre què és i què no és autolesionarse i sota quins paradigmes es construeix el terme. És per això que presentaré de forma molt sintètica algunes de les propostes que es debaten en l'àmbit biomèdic i que fan referència a la categorització de la conducta autolesiva com a trastorn mental.

Des del sorgiment de l'interès mèdic per la qüestió de l'autolesió corporal, tots els articles revisats s'esforcen a tractar de definir i justificar l'ús d'un terme o un altre. No obstant això, he detectat que, tot i l'esforç de realitzar una definició acurada, un mateix autor pot emprar diferents termes en diferents publicacions. És a dir, que sembla que en la selecció no existeix consens i resulta bastant complex realitzar un seguiment o establir un criteri únic i raonable de classificació.

\begin{tabular}{|l|l|}
\hline Autolesión & Taboada (2009); Mosquera (2008) \\
\hline Self-harm & $\begin{array}{l}\text { Hawton, K., Rodham, Harris i Evans (2003, 2005, 2009, 2010); } \\
\text { Johnson i Day (1992); Beaseli (2000); Fortune, Sinclair i Hawton } \\
\text { (2008); Nicholson (2004) }\end{array}$ \\
\hline Self-mutilation & $\begin{array}{l}\text { Menninger (1935, 1938); Favazza (1988, 1989, 1993, 1997, 2002); } \\
\text { Conterio (1988, 1989, 2002); Lane (2002); Rosenthal (1989, 1993, } \\
\text { 1997); Matsumoto, Azekawa i Yamaguari (2004); Schröer i Sperhake } \\
\text { (2001); Zlotnick, Mattia i Zimmerman (1999); Ross, Heath (2002); } \\
\text { Levenkron (1998). }\end{array}$ \\
\hline $\begin{array}{l}\text { Deliberate self- } \\
\text { harm }\end{array}$ & $\begin{array}{l}\text { Howton (1998, 1999, 2008), Rodham (2009); Cray (2009); Hawton, } \\
\text { (2002); Gratz (2001); Mangnall i Yurkovich (2008). }\end{array}$ \\
\hline
\end{tabular}




\begin{tabular}{|l|l|}
\hline Self-injury & $\begin{array}{l}\text { Hawton (1978); Favazza (1996); Alper i Peterson (2001); Bochian } \\
\text { (2002); Ross, Heath i Toste (2009); Wilkinson i Goodyer (2011); } \\
\text { Klonsky (2011); Stein, Lilenfeld, Wildman i Marcus (2004); Inkle } \\
(2010) .\end{array}$ \\
\hline $\begin{array}{l}\text { Non-suicidal self- } \\
\text { injury }\end{array}$ & $\begin{array}{l}\text { Petermann i Nitkowski (2011); Klonsky (2011); Lloyd-Richardson, } \\
\text { Perrine, Dierker i Kelley (2007); Adrian, Zeman i Erdlay (2010); } \\
\text { Klonsky (2010). }\end{array}$ \\
\hline $\begin{array}{l}\text { Self-inflicted } \\
\text { violence }\end{array}$ & Alderman (1998); Brown i Bryan (2007). \\
\hline Self-wounding & Brooksbank (1985); Tantum i Whittaker (1992). \\
\hline $\begin{array}{l}\text { Self injurious } \\
\text { behaviour }\end{array}$ & $\begin{array}{l}\text { Claes i Vandereycken (2001, 2007); Herpertz (1995); Shearer } \\
\text { (1994); Solomon i Farrand (1996). }\end{array}$ \\
\hline Parasuicide & Hawton (1996). \\
\hline Cutting & McCornick (2002); Hall i Place (2010); Levenkron (1998). \\
\hline
\end{tabular}

Quadre 2. Revisió dels conceptes emprats en la literatura revisada. Elaboració pròpia

Si bé, tal com hem vist, no existeix unanimitat en l'ús de termes, proposo utilitzar el concepte acció autolesiva corporal per referir-me a totes aquelles accions on, sense que existeixi voluntat de mort, s'inscriuen i expressen a través del cos experiències, emocions, vivències i sensacions d'entumiment emocional". Val a dir que prefereixo emprar el terme acte o acció en lloc de conducta - behaviour - perquè d'aquesta manera pretenc posar distància amb els treballs de tall psicopatològic existents. Em refereixo a autolesions per desmarcar-me de d'altres formes d'inscripció corporal socialment acceptades (com tatuatges o pírcings), i, finalment, considero molt important el fet d'incorporar i reivindicar el cos com a simple precisió del terme, ja que hem de tenir sempre present que l'acció es realitza en, per i des del cos.

En la descripció del perfil tipus, Favazza (1988) afirma que l'autolesió afectava un $1 \%$ de la població nord-americana i que, d'aquest, un $97 \%$ eren dones. The portrait of the typical self-injurer ha estat definit per Favazza $(1988: 284)$ com "white women, in her late twenties who began hurting herself at the age of fourteen. She had injured herself at least 50 times, usually by cutting but also using other methods, including burning or self-hitting"; M. Galley (2003: 4) les defineix com "bright, sensitive, helpful to others, caretakers of their fri- 
ends and family, good listeners, above average students, and invisible. They are very creative, artists and neat kids, but ones who don't make their needs well known", i per a Craigen (2009) l'autolesió és la "nova anorèxia" que afecta específicament dones joves.

Segons Ross i Heath (2002), "girls are generally considered more frequent participant than boys" i, segons Kiselica i Zila (2001), "like eating disorders, self-injury is seen as located primarily among an educated, middle-or-upperclass population". Per a Mueller (2004), "individuals who self-cut may be very academic, involved in athletics and extracurricular activities [...], individuals who self-cut tend to have shy personalities and lower self-esteem". Per a Froeschle i Moyer (2004) existeixen diferències de gènere amb relació als significats de l'autolesió; així, doncs, assenyalen que mentre per als nois l'autolesió te un significat de ritu de pas, en les noies l'autolesió es realitza en privat i sol ser emocionalment més intensa. Per a Levenkron (1998: 46), "the person who choses this action is someone who experiences herself as powerless. She may not be docile, timid or shy in public; she may be quite outgoing. [...] She is often plagued by a fear of punishment [... . Like the anorexic, she may feel that she has no one to depend upon or to trust with her emotions". Pel que fa a l'edat d'inici, s'assenyala que l'acció autolesiva s'inicia normalment cap als 12-14 anys.

El biaix de gènere en la literatura quantitativa revisada poques vegades s'aborda quan es tracta d'establir un raonament causal i crític de les dades epidemiològiques. Sobre això, i arran del treball realitzat específicament en comunitats virtuals, crec que és important destacar la presència de nois que sautolesionen. Tanmateix, aquests nois, a causa del doble estigma que pateixen (pel fet de realitzar una acció considerada femenina i a més considerada una conducta desviada) moltes vegades romanen en l'anonimat i troben en l'espai asèptic de la virtualitat el lloc idoni per a la seva exteriorització.

Amb relació a la construcció del perfil tipus o model de dona que śautolesiona, cal reflexionar sobre com, igual que va succeir amb la propagació del patró histèric durant el segle XIX (Hepworth, 1999) —en què la histèria va ser considerada la bogeria femenina per excel+lència - i després, unes dècades més tard, va succeir amb el patró de l'anorèxia nerviosa (Gracia, 2005), la difusió del prototip fa que es tractin d'imitar d'acord amb l'esquema proposat aquest tipus de conductes. És el que s'anomena efecte nocebo (Cannon, 1945) del diagnòstic i que, com veurem més endavant, pel fet d'impulsar un determinat patró con- 
tribueix que s'incorporin interpretacions que promouen tendències cronificadores i lectures sobre l'addicció —un dels models explicatius biomèdics parla de la interpretació endorfínica i addictiva - de l'acció.

Dels diferents tractaments i interpretacions, magradaria destacar el percebut decalage durant el treball de camp, entre els models explicatius mèdics - extrets de les entrevistes a psicòlegs i psiquiatres - i els sentits de l'acció autolesiva que s'extreu dels relats dels informants.

D'acord amb els testimonis de psiquiatres recollits durant el treball de camp, les explicacions més comunes de l'acció autolesiva tenen a veure amb:1) el desig de cridar l'atenció; 2) una acció addictiva que apareix com a conseqüència de l'augment del nivell d'endorfines que es produeix amb l'autolesió; 3) una resposta a emocions bloquejades, normalment causades per abusos sexuals, físics i psicològics produïts durant la infantesa.

Dels relats dels informants, el sentit de l'acció autolesiva té a veure amb emocions reprimides, buidor interior, soledat, ansietat, angoixa i dolor controlat que reconnecta.

Des del punt de vista biomèdic, les aproximacions a l'etiologia i tractament de les autolesions corporals vénen donades per tres models.

1) El model biologic: centrat sobretot a trobar un raonament quantificable que pugui explicar l'autolesió. Des d'aquest model es parla de desequilibris en els nivells de concentració de serotonina, segregació de beta-endorfines i baixos nivells de concentració de làcid 5-hidroxiindolacètic.

2) El model conductista: fa sobretot referència a conductes mal apreses que s'expressen amb l'autolesió. El model conductista inclou també la tendència sexual sadomasoquista.

3) El model psicodinàmic: fa referència a patiments de tipus emocional que s'expressen a través del cos.

Aquests models fan referència específicament a l'autolesió corporal com un criteri diagnòstic (segons DSM-IV-TR) lligat als diagnòstics següents: esquizofrènia $\mathrm{i}$ altres trastorns psicòtics — trastorn esquizofreniforme, trastorn esquizoafectiu, trastorn delirant, trastorn psicòtic breu, trastorn psicòtic compartit, trastorn psicòtic induït per substàncies - i trastorns de l'estat d'ànim (trastorns depressius, trastorns d'ansietat — trastorn obsessiu compulsiu-, trastorns somatomorfs, trastorns sexuals i de la identitat sexual, trastorns de la conducta alimentaria, els anomenats "trastorns del control dels impulsos no 
classificats en altres apartats") i els trastorns de la personalitat (trastorn esquizoide i el trastorn límit de la personalitat).

En el darrer número de la revista European Child \& Adolescent Psychiatry, Paul Wilkinson i Ian Goodyer (2011) assenyalen que ni el DSM-IV ni el CIE10 parlen de l'autolesió com a etiqueta nosològica, però es preveu que en la propera edició del DSM-V aparegui com una síndrome sota l'etiqueta diagnòstica de non-suicidal self-injury (NSSI). Segons els autors, aquest diagnòstic resulta útil per tres raons: en primer lloc, perquè millorarà la comunicació entre els terapeutes; en segon lloc, perquè reduirà els problemes de salut que poden derivar de la falta d'un diagnòstic específic, i, finalment, perquè millorarà la previsió de tractament i el pronòstic de les pacients.

Els criteris per al diagnòstic de NSSI en el DSM-V, segons Wilkinson i Goodyer (2010: 4) són: ${ }^{4}$

A. En el darrer any i com a mínim durant cinc dies, la persona es propicia autolesions sobre el cos que poden produir sagnat i blaus mitjançant, per exemple: talls, cops, fricció excessiva, cremades, amb una finalitat no sancionada per la societat i que es realitzen amb la intenció de produir un dany lleu o moderat. L'absència d'ideació suïcida és referida pel pacient o pot deduir-se per l'ús d'instruments i de mètodes que sap que no tenen una potència letal. El comportament no és de naturalesa comuna i trivial com arrencar-se crostes o mossegar-se les ungles.

B. Lautolesió śassocia amb, com a mínim, dues de les característiques següents:

1. Els sentiments i pensaments negatius. La depressió, l'angoixa, la tensió, l'enuig i l'autocrítica que ocorren en el període immediatament anterior a l'autolesió.

2. Abans de realitzar l'acció, sensació que és difícil resistir la temptació de no lesionar-se enfront dels sentiments anteriorment descrits.

3. La sensació de tenir ganes d'autolesionarse és freqüent, tot i que no sempre es materialitzi l'acte.

4. Lacció autolesiva sempre té una finalitat, que tant pot ser el fet d'alleugerir una sensació negativa, estat cognitiu o dificultats interpersonals, o

4. Traducció pròpia de la versió original en anglès. 
la inducció d'un estat emocional positiu. El pacient s'hi anticipa durant l'autolesió o immediatament després.

C. El comportament autolesiu i les seves conseqüències provoquen un malestar clínicament significatiu en les relacions interpersonals, acadèmiques o altres tipus de relacions.

D. Lacció no es realitza exclusivament en estat de psicosi, deliri o intoxicació. En els individus amb un trastorn del desenvolupament, l'autolesió no respon a un patró estereotípic repetitiu. La lesió no pot ser explicada per un trastorn mental o mèdic (trastorn psicòtic, trastorn del desenvolupament, retard mental o síndrome de Lesh-Nyan).

Sobre els criteris diagnòstics del DSM-V, cal senyalar dues qüestions. La primera té a veure amb el sempre latent arbitrari normal-anormal, és a dir, ens permet objectivar el procés mitjançant el qual un signe es converteix de la nit al dia en símptoma i a partir d'aquí es crea el diagnòstic, i la segona qüestió fa referència a l'actual tendència medicalitzadora de tots aquells comportaments que, interpretats com a conductes desviades, són etiquetats com a entitats patològiques pel fet que no poden ser descodificats des del marc de la racionalitat estrictament biomèdica.

Aquesta situació és equiparable al que va passar ara ja fa uns quants anys amb els trastorns de la conducta alimentària (TCA). Amb relació als TCA, la consideració com a malaltia mental ha patit una evolució significativa. En el DSM III (1982), els trastorns de la conducta alimentària (anorèxia nerviosa, bulímia nerviosa, pica, trastorn per ruminació i trastorns de la conducta alimentària no especificats) es consideraven "trastornos de inicio en la infancia, niñez o adolescencia”, mentre que en el DSM-IV (1994) ja apareixien com a diagnòstics específics: l'anorèxia, la bulímia i els TCANES (trastorns de la conducta alimentària no especificats) caracteritzats per "alteraciones graves de la conducta alimentaria" (DSM-IV Tr, 2004: 653) sense tenir en compte, com assenyala Zafra (2008), el paper que juga el menjar en tot l'entramat de relacions que es generen entre el plaer-benestar i el conflicte-malestar. Amb això, crec que, lluny de simplificar el problema, la reducció de l'autolesió a un diagnòstic (NSSI) i als seus criteris de classificació fa que es perdi el sentit del símptoma, la vivència de l'acció en el seu context, que es perdin les narratives, 
que es perdin els sentits que fan que els joves tendeixin a expressar mitjançant el cos els seus malestars.

Si bé som conscients que el biaix de gènere — amb una proporció de $7 / 1$ segons la Sociedad Española de Psiquiatria (2009) — és un element que cal tenir en consideració en la manifestació del signe, creiem que sobre la dada cal plantejar-se el paper que juga la construcció del cos i de la subjectivitat femenina en tot aquest procés. Com a crítica a la proposta de la nova categoria diagnòstica en la propera edició del DSM, considerem que, més enllà de la classificació com a síndrome o com a trastorn, les autolesions corporals ens parlen d'experiències de sofriment encarnat que en el moment que siguin legitimades per la nosologia psiquiàtrica passaran a reduir i homogeneïtzar una sèrie d'experiències en una mateixa etiqueta que silenciarà, sota la interpretació de la desviació, tot un cúmul de situacions que són les que desemboquen en la realització de l'acció.

\section{De la psicosomàtica a la sociosomàtica. El treball amb narratives}

Una vegada descrites les principals aportacions amb relació a l'acció autolesiva corporal a través dels tres models explicatius (biològic, cognitiu-conductista i psicodinàmic) i un cop detallada la proposta que apareixerà definida en la propera edició del DSM-V, el primer que ens esquitxa des de l'existència d'aquests tres paradigmes clarament diferenciats segons etiologia i corrent dominant és la falta d'un model que doni compte de la complexitat causal amb què ens trobem quan parlem d'autolesions corporals en joves. El decalage entre els models explicatius mèdics, molt centrats en l'autolesió com a símptoma en el trastorn límit de la personalitat, inespecífic, histrionisme i addicció, i els models explicatius de les pacients (nervis, angoixa, entumiment i relax) fa que sigui necessari recuperar aspectes de la vivència (illness), la interpretació d'aquesta vivència (dimensió de l'experiència) i acció al si del context social actual.

Per a la Míriam, de 15 anys, diagnosticada de TLP i membre del forum Soytlp.com, més enllà del signe visible hi ha tota una sèrie d'experiències prèvies que son les que culminen en l'autolesió:

La autolesión yo la percibo como una forma de sacar afuera todo el dolor que me invade. Cuanto más profundo es el corte, mayor es el dolor que trato 
de neutralizar, porque también lo es la necesidad de librarme de él. Lo peor viene después, me siento culpable cuando veo los cortes pero es... no sé como explicártelo. No es dolor lo que siento. Me siento calmada. Me siento relajada. (Míriam, 15 anys)

Amb relació als models explicatius que ja s'han descrit amb anterioritat, una de les principals qüestions observades, tant en la revisió bibliogràfica com en els relats als professionals entrevistats, és la unidireccionalitat de les hipòtesis explicatives i la forma com saborden terapèuticament. A partir de la concepció de la malaltia (evidència orgànica) o del símptoma (dimensió subjectiva), el model biològic busca interrelacions mitjançant evidències que poden ser mesurades (nivells de serotonina, beta-endorfines, reacció a estímuls dolorosos, variació de la banda theta a l'encefalografia basal, entre d'altres). El model conductista incorpora aspectes relatius a l'aprenentatge i a la vivència d'experiències traumàtiques que poden desembocar en autolesió. Finalment, el model psicodinàmic és potser el que des de la interpretació del símptoma i el valor del relat estableix un model no tan unidireccional.

Per tal d'aprofundir en els diferents nivells que cadascun d'aquests models aporta, veure les seves limitacions i construir la nostra interpretació, utilitzarem els conceptes analítics - illness, sickness i disease - i la noció de models explicatius d'Arthur Kleinman (1988: 5). En aquest sentit, el model de Kleinman ens permet recuperar, a més a més de la dimensió fenomenològica (cos - acció autolesiva - experiència) la idea de l'autolesió com un llenguatge de patiment encarnat.

Per a Kleinman, el concepte illness fa referència a l'experiència, a la vivència de la malaltia. El terme disease serveix per explicar el punt de vista mèdic, més orgànic, i sickness per explicar la dimensió social de la malaltia. Analíticament, el concepte de models explicatius (Kleinman, 1988) ens serveix per donar compte de les nocions/construccions amb relació a un determinat episodi de malaltia/malestar sobre la base dels agents implicats en el procés clínic. Parlar de models explicatius es parlar del procés de transacció entre el model explicatiu del pacient i el model explicatiu del metge, els seus punts de convergència i dissonància. I és que, tal com hem vist, és precisament en aquest decalage de models explicatius que es perd el significat del símptoma. 
Si bé tots o gairebé tots els treballs que hem revisat parlen de l'existència d'una diferenciació de gènere en favor de les dones, per què això es dóna com una simple dada descriptiva? Per què no es parla dels condicionants socials i culturals en què es troben immerses aquestes dones? I què passa amb els casos de nois que sautolesionen?

Amb relació al biaix de gènere, sobre la necessitat de reivindicar la multidimensionalitat/ complexitat del fenomen i amb l'objectiu de recuperar les dimensions culturals i simbòliques que hi ha al darrere dels significats de les autolesions, considerem que l'aplicació d'una perspectiva hermenèutica que aprofundeixi en les dimensions comprensives i explicatives de l'autolesió en el seu context ens duu a interpretar l'autolesió com una acció en la qual, a través dels talls i les inscripcions, el cos anònim es transforma en text amb capacitat discursiva (amb expressions literalment i carnalment inscrites com ara: pain, alone, lonely, ugly, worthless, lost, dead, I die, fuck you, sad, stupid, numb, this one is for you, kill me, release). No obstant això, hem de tenir en compte que aquesta idea de cos-text (molt foucaultiana, d'altra banda) no deixa de ser el punt de partida de la recerca, ja que és a partir d'aquí, a partir del cos i a partir de la lesió, que entrem metafòricament, carnalment i analíticament en la dimensió intersubjectiva, fenomenològica $\mathrm{i}$ interpretativa de l'experiència. Aquest abordatge teòric ens obliga a repensar l'autolesió com "una forma elemental del acontecimiento" (Augé, 1991), com un punt de partida a partir del qual buscar la lògica de l'acció, de la seva expressió mitjançant el cos i la seva correspondència amb els diferents ordres de la vida social. Considerem, doncs, que les aportacions que s'han fet des d'un posicionament feminista i que presenten interessants reflexions sobre la normal exclusió de l'experiència de ser dona (sobretot en l'àmbit del model psiquiàtric hegemònic actual), a més a més de les aportacions feministes postestructuralistes (Butler: 2000, 2001, 2002) que focalitzen sobre l'experiència d'aquestes dones en el context de les realitats socials en què viuen, ens servirà per interpretar alguns dels sentits que romanen latents en les experiències de la Noe i de la Paula.

La Noe té 23 anys i escriu cada dia al portal Universotlp.com. Està diagnosticada de trastorn limit de la personalitat (TLP) i s'autolesiona des que tenia 12 anys. Els motius que la duen a fer-ho tenen a veure amb emocions i sentiments desbordants, normalment culpa i ràbia, que no sap com expressar i canalitza a través del cos. Al cap d'uns anys de començar a autolesionar-se, la Noe pren 
consciència que "esta conducta no es normal" i cerca ajut psicològic. Una vegada dins el circuit medicalitzador de l'acció, se li diagnostica un trastorn límit de la personalitat $\mathrm{i}$ inicia, a partir d'aquest moment, la seva trajectòria terapèutica. Reproduïm el primer dels seus apunts publicat a Universotlp.com l'any 2007 i que titula "Aprendiendo a vivir":

Nací en una familia lo que se conoce como estructurada, una buena educación y todo lo que el núcleo familiar puede ofrecerte, con sus cosas pero como todo. El problema o la circunstancia que hoy conscientemente reconozco como la causa principal de haber desarrollado el Trastorno Límite de Personalidad, sin lugar a dudas fue las violaciones reiteradas durante varios años de mi infancia. El período exacto no sabría decir, pero las edades rondaban entre los 5 y los 8 años.

Siempre fui una niña con miedos, con inseguridades y por lo que sé ahora sumamente inestable; a la edad de 12 años ya estaba jugando a hacerme daño': heridas con tijeras, a cada enfado las muñecas de mis manos eran rozadas contra los edificios para simplemente provocarme dolor. La explosión surgió a los 16 cuando mi obsesión era morirme, desaparecer, nunca he intentado suicidarme, sí pequeños sustos pero no con la intención clara de matarme, si no de dormir y huir del estado en el que me encontraba, una vez terminé en urgencias por ingesta de pastillas pero no fue nada importante.

Pasé por mi primera experiencia de psiquiatra y psicólogo, pero nada destacable porque su intención no era diagnosticarme nada, sino 'pasar su tiempo' conmigo... Puede sonar despectivo pero no lo es, fue la realidad, duré muy poco tiempo para alivio de nuestra querida Seguridad Social, menos gastos y menos tiempo que emplear con una niña que solo 'pretendía llamar la atención' y poco más. Pero a pesar de mi experiencia puedo decir que hay profesionales buenos y profesionales no tan buenos, un trastorno poco estudiado y pocos profesionales especializados en su tratamiento, por lo cual podemos pasar por cualquier otro diagnóstico que no sea el adecuado, y así pasarnos media vida sin encontrar nuestro sitio...

Los años pasaban y yo iba de estados muy buenos a caóticos en cuestión de semanas, días e incluso horas, mi mente no entendía qué era lo que pasaba; si no quería morirme, ¿̨por qué lo pensaba?; si no quería hacer daño ni a mí ni a los demás, ¿por qué lo hacía?, por lo que esos sentimientos de culpabilidad, ansiedad, dolor, los recuerdo desde que era bien pequeña... 
Hasta que la situación fue empeorando mes a mes y año tras año, hasta que a mis 22 años sufrí una de las crisis más fuertes que recuerdo, así que por propia decisión terminé en una consulta privada, con la única y clara intención de saber la verdad. Me prometí que esto cambiaría, que ya no valía el 'lo intentaré,' venga, ya se pasará; eso ya no era suficiente, yo necesitaba salir de todo esto. Fue justamente en ese momento cuando fui diagnosticada de TLP; fue duro aceptar que pasaba algo, que tenía un nombre y lo peor que cómo afrontaría todo esto. Un mes después decidí contarle a mi familia, y a algunos amigos/as lo que pasaba. Con algunos tuve más suerte que con otros, unos se empeñaban en dar la espalda a todo lo que significara trastorno, tener un problema... En la terapia descubrí el significado de mi trastorno, pensamientos y sentimientos que tenía que no estaban acorde a la realidad que en verdad existía, darme cuenta de las cosas que tenía dentro y que el no hablar y no exteriorizar lo que sentía hacía que me bloqueara y terminará con mis cambios de humor, descubrí el significado de autolesionarme como forma de huida, descubrí todas esas cosas positivas de mí que había olvidado, aprendí a analizar cada una de las situaciones y sentimientos y cómo hacerles frente poco a poco.

Aprendí que la infancia marca, que se queda dentro, que las cosas no se olvidan por no contarlas... He de decir que nunca he considerado que tenga un trauma por las agresiones sufridas, los recuerdos no me impiden hacer una vida más o menos normal, no sé cómo lo hice, quizá influya el hecho que no tengo esa parte de mi vida bloqueada, no me cuesta recordar ninguna de las situaciones y momentos, por 'suerte' o por desgracia recuerdo cada uno por pequeño que sea de esos momentos, no necesito hacer terapia para sacarlo fuera y que no me bloquee.

La Paula té 30 anys, la vaig conèixer a finals de setembre del 2009; va ser ella qui, coneixent el meu treball, es va posar en contacte amb mi. Per la Paula les autolesions corporals tenen molt a veure amb vivències "d'angoixa, dolor, però no dolor físic. Dolor emocional. Impotència. Desesperació. Soledat. Incomunicació.... La Paula relata els episodis d'autolesió com a experiències d'un patiment mental i emocional molt fort. Un patiment que no podia expressar mitjançant la paraula:

Mira, jo crec que el secret no es l'autolesió. El secret es allò que no es vol abordar. Perquè per mi el tema de les autolesions, per mi és el més suau de 
tot. L'important és el que porta una persona a autolesionar-se. Veure per què s'expressa com sexpressa.

En el meu cas, jo era petita, estava vivint una situació molt desbordant: el meu entorn, els meus referents... No tenia referents adults cuerdos [sic] i no trobava la manera com canalitzar el meu patiment, com canalitzar les meves emocions. Llavors, és clar, com que aquell era el meu únic entorn i per mi era normal però jo estava patint, vaig arribar a pensar que no eren els altres els que estaven bojos, sinó que era jo.

Arriba un moment que la Paula pensa que "està boja" i ens relata que la seva germana és la primera d'esclatar en un context que defineix com de "bogeria familiar normalitzada".

Hi va haver un punt en el que es va visibilitzar en l'àmbit familiar la bogeria. Va arribar un punt que ma germana gran devia tenir uns 13 anys, i va explotar visiblement. Va començar a sortir, a beure, bufff... Jo què sé. A drogar-se, a autolesionar-se, ma germana gran de sobte es va transformar. Aquesta és la meva vivència de petita, eh! De quan el teu món adult sét desmunta [sic]. Jo he viscut molt les conductes autolesives de ma germana i això a mi m'ha afectat molt personalment. Però torno a dir-te que no tant el mal físic com el desbordament emocional. Sobre autolesions de ma germana, doncs des de cremar-se amb burilles fins a tancar-se al lavabo i intentar tallar-se les venes, $i$ jo estava allí amb ella, intentant obrir la porta. Mmm... beure ampolles de colònia, què més? És que també l'autolesió i la violència es barregen perquè ara estava pensant també a trencar un vidre amb el puny, no? Que s'està autolesionant i està expressant... Està canalitzant la ràbia i l'odi i ho està fent i en realitat s'està fent mal a ella mateixa.

Amb relació a les lectures que es donen a l'autolesió, específicament relacionades amb la interpretació addictiva, la Paula comenta:

Potser hi és, no ho sé, però en definitiva tu ets addicte a l'autodestrucció. Però no és una addicció, no ets addicte. Tu estàs atrapat, tu estàs fugint, tu ets addicte a la fugida. És que no faria servir mai el terme addicció; també em fa ràbia perquè per mi es una explicació senzilla i biologicista d'un tema supercomplex i, a més a més, crec que pot fer mal.

Dels fragments de relat que he presentat, se n'extreu que els significats que es donen a l'autolesió i els orígens que la Noe i la Paula atribueixen al seu pati- 
ment tenen a veure amb un sofriment que expressen a través de l'autolesió i que en tots dos casos va ser causat pels abusos que van patir quan eren petites. Tal com ja he plantejat, el marc que possibilita l'aproximació a les seves històries té a veure amb el marc contextual (sociosomàtic) en què l'autolesió com a signe de sofriment incorporat aflora. En el relat de la Noe, per exemple, veiem com la interpretació psicosomàtica es perd sota el paraigua de l'etiqueta, tractant de reconduir el símptoma i d'aïllar l'individu de la seva experiència.

\section{Conclusions}

How will you know I'm hurting if you cannot see my pain?

To wear it on my body tells what words cannot explain

C. Blount, 19 anys

La pregunta latent sobre la qual es construeix aquest treball té a veure amb els marcs interpretatius en què l'acció autolesiva corporal es converteix en un acte-significant. La nostra principal aportació en aquest àmbit té a veure amb la manera com l'articulació del paradigma hermenèutic, juntament amb la consideració de l'autolesió corporal com un fet social de naturalesa relacional, ens ha permès superar el signe visible i captar el mapa semàntic en el qual s'inscriuen els sentits de l'autolesió. Aquesta deferència ens ha permès també, partint de la naturalesa de l'acte, posar sobre la taula l'arbitrari sobre el qual es construeixen els marcs legitimadors de la interpretació normal/anormal vinculats a l'acció.

Una altra de les qüestions que hem tractat de plantejar té a veure amb la manera com l'etnografia ens ha permès confrontar, d'una banda, els models explicatius mèdics que construeixen l'acció autolesiva corporal com a signe i, de l'altra, els discursos de les joves que s'autolesionen corporalment, i dels discursos de les quals — narrats i carnals - emergeix tota una sèrie de sentiments que es canalitzen a través del cos. Precisament d'aquest percebut decalage i de les evidències extretes, es posa de manifest la necessitat de construir un nou paradigma menys medicalitzador i que eviti precisament l'efecte psiquiatritzador amb tendència a la cronificació de l'actual model.

Si bé en els significats que les nostres informants estableixen al voltant de les autolesions es barregen el dolor, la tristesa, la ràbia, l'esmussament emocional amb sentiments del culpa, els desigs d'abstracció, l'autocàstig, la soledat i la buidor, la nostra proposta té a veure amb la superació del paradigma semiòtic 
del cos com a text, precisament perquè mitjançant la inscripció carnal accedim als mons d'experiència d'aquests joves. D'alguna manera el nostre procediment seria totalment a la inversa del plantejament de la psiquiatria clínica. Si bé com assenyala Good (2003: 33) "la misión de la medicina clínica [... es transformar los síntomas, decodificar las expresiones simbólicas del paciente en términos de sus referentes somáticos subyacentes", el nostre objectiu busca retornar l'experiència que el model de medicina clínica ailla en l'individu cap al món social, i és que només des del seu context el símptoma pot ésser descodificat.

\section{Bibliografia}

Ackerknecht, E. (1971). Medicina y antropología social: estudios varios. Madrid: Akal.

Bourdieu, P. (1976). El oficio de sociólogo: presupuestos epistemológicos. Madrid: Siglo XXI.

Butler, J. (2000). “Imitación e insubordinación de género”. Revista de Occidente, núm. 235 (desembre).

- (2001). Mecanismos psíquicos del poder: teorías sobre la sujeción. Madrid: Cátedra.

- (2002). Cuerpos que importan: sobre los limites materiales y discursivos del "sexo". Buenos Aires: Paidós [1996].

Cangilhem, G. (1971). Lo normal y lo patológico. Buenos Aires: Siglo XXI.

Cannon, W. B. (1945)."Voodoo death”. American Anthropologist, núm. 44 (2), p. 169-181,

Devereux, G. (1980). Normal and abnormal. In basic problems in ethnopsychiatry. Chicago: University of Chicago Press.

Durkheim, E. (1987). Las reglas del método sociológico. Torrejón de Ardoz: Akal [1895].

DSM-IV-TR (2002). Manual diagnóstico y estadístico de los trastornos mentales. Madrid: Elsevier Masson.

Favazza, A. (1988). "What do we know about affective disorders?". American Journal of Psychiatry, núm. 143 (10), p. 1328.

Froeschle, J.; Moyer, M. (2004). "Just cut it out: legal and ethical challenges in counseling students who self-mutilate". Professional School Counseling, núm. 7, p. 231-235. 
Girard, R. (1986). El chivo expiatorio. Barcelona: Anagrama.

Goffman, E. (1970). Estigma. La identidad deteriorada. Buenos Aires: Amorrortu.

Good, B. (1994). Medicina, racionalidad y experiencia. Barcelona: Bellaterra.

Gracia, M., et al. (2005). Proyecto "Género, dieting y salud. Un análisis transcultural de la incidencia de los trastornos del comportamiento alimentario en las mujeres". Instituto de la Mujer, 2003-2005.

Harrison, K. (1993). Exposure. Nova York: Warner Books.

Hawton, K., et. al. (2008). "Deliberate self-harm within an international community sample of young people: comparative findings from the Child \& Adolescents Self-harm in Europe (CASE) Study". Journal of Child Psychology and Psychiatry, núm. 49 (6), p. 667-677.

Hepworth, J. (1999). The social construction of anorexia nervosa. Londres: Sage.

Kiselica, M. S.; Zila, L. M. (2001). "Understanding and counseling selfmutilation in female adolescents and young adults". Journal of Counseling $\mathcal{E}$ Development, núm. 79, p. 46-52.

Kleinman, A. (1988). The illness narratives: suffering, healing and the buman condition. Nova York: Basic Books.

Levenkron, S. (1998). Cutting. Nova York: W. W. Norton and Company.

LÉvi-Strauss, C. (1964). Antropología estructural. Barcelona: Paidós.

Madge, N.; Hewitt, A.; Hawton, K., et. al. (2008). "Deliberate self-harm within an international community sample of young people: comparative findings from the Child \& Adolescents Self-harm in Europe (CASE) Study". Journal of Child Psychology and Psychiatry, núm. 49 (6), p. 667-677. Menéndez, E. (1985). “Aproximación crítica al desarrollo de la Antropología Médica en América Latina”. Nueva Antropología (Mèxic), vol. VII, núm. 28, p. 11-28.

- (1997). "Holísticos y especializados. Los usos futuros de la Antropología". Nueva Antropología (Mèxic), núm. 52, p. 9-38.

- (2003)."Modelos de atención de los padecimientos: de exclusiones teóricas y articulaciones prácticas". Ciencia y Saude Colectiva, núm. 8 .

Mueller, K.; Nyhan, W. L. (1982). "Pharmacologic control of pemolineinduced self-injurious behavior in rats". Pharmacology, Biochemistry and Behavior, núm. 17, p. 957-963. 
Prince, R. (1985)."The concept of culture-bound sindromes: anorexia nervosa and brain fag". Social Science and Medicine, núm. 21, p. 197-203.

Ricoeur, P. (2003). Teoría de la interpretación, discurso y excedente de sentido. Mèxic: Siglo XXI.

Ross, S.; Heath, N. L. (2002). "A study of the frequency of self-mutilation in a community sample of adolescents". Journal of Youth and Adolescence, núm. 31, p. 67-77.

Turner, V. (1980). La selva de los simbolos: aspectos del ritual ndembu. Madrid: Siglo XXI.

Van Dongen, E. (2004). Worlds of psychotic people: wanderers, bricoleurs and strategists. Londres: Routledge.

Wilkinson, P; Goodyer, I. (2011). "Non-suicidal self-injury”. European Child and Adolescent Psychiatry, núm. 20 (2), p. 103-108.

ZaFra, E. (2008)."Los trastornos del comportamiento alimentario como 'estares alimentarios': entre el placer (bienestar) y el conflicto (malestar)". Dins Antropología de la medicina, metodologías e interdisciplinariedad: de la teoría a las prácticas académicas y profesionales. XI Congreso de Antropología: "Retos teóricos y nuevas prácticas". Sant Sebastià: Ankulegi Antropologia Elkartea. 